Revista Eletrônica de Direito Processual - REDP.

Rio de Janeiro. Ano 10. Volume 17. Número 2. Julho a Dezembro de 2016

Periódico Semestral da Pós-Graduação Stricto Sensu em Direito Processual da UERJ

Patrono: José Carlos Barbosa Moreira. ISSN 1982-7636. pp. 76-100 www.redp.uerj.br

\title{
AS DUAS TÉCNICAS DE PROCESSO COLETIVO: AÇÕES COLETIVAS E CASOS REPETITIVOS ${ }^{1}$
}

\section{THE TWO TECHNIQUES OF COLLECTIVE PROCEDURE: COLLECTIVE ACTIONS AND REPETITIVE CASES}

Carla de Jesus Brandão

Discente do curso de graduação em Direito pela Universidade Federal do Espírito Santo - UFES, membro do núcleo de pesquisa "As colisões de direitos fundamentais com caráter de princípios no novo CPC". carlajbrandao@gmail.com

Juliana Provedel Cardoso

Mestranda em Direito Processual pela Faculdade de Direito da Universidade Federal do Espírito Santo - UFES, bolsista pela Fundação CAPES - Ministério da Educação, monitora das disciplinas Processo Coletivo e Procedimentos Especiais (Processo Civil VI) e Teoria Geral do Direito no curso de graduação em Direito da UFES. Pesquisadora vinculada ao Grupo de Pesquisa Fundamentos do Processo Civil Contemporâneo, do Programa de Mestrado em Direito da Universidade Federal do Espírito Santo - UFES. Advogada. julianaprovedel@gmail.com

RESUMO: $O$ artigo trata do sistema de julgamento dos casos repetitivos positivado pelo Código de Processo Civil de 2015 enquanto espécie do gênero do processo coletivo brasileiro. Examina-se conceitos essenciais do processo coletivo bem como faz-se uma análise comparativa entre as ações coletivas para a tutela de direito difusos, coletivos stricto senso e individuais homogêneos com os novos institutos processuais destinados a contingenciar a litigiosidade de massa, o Incidente de Resolução de Demandas Repetitivas (IRDR) e os Recursos Especiais e Extraordinários Repetitivos (REER).

PALAVRAS-CHAVE: Processo Civil; Processo coletivo; Ações Coletivas; Casos repetitivos; Litígios de massa.

\footnotetext{
${ }^{1}$ Artigo recebido em 29/09/2016 e aprovado em 28/11/2016.
} 
ABSTRACT: The article deals with the trial system of repetitive cases by the Civil Procedure Code of 2015 as a species of the Brazilian collective process genre. Analyzes essential concepts of the collective process and makes a comparative analysis of collective action for the protection of brazilian collective rights with the new procedural institutes designed to impound the mass litigation, the incidente of repetitive claims and repetitive appeals.

KEYWORDS: Civil Procedure. Collective process. Collective actions. Repetitive cases. Mass claims.

SUMÁRIO: Notas introdutórias. 1. O processo coletivo e seus diferentes modelos: conceituações necessárias. 2. As duas técnicas de processo coletivo: as ações coletivas e os casos repetitivos. 2.1. Objeto. 2.2. Caráter opt in ou opt out. 2.3. Legitimidade 2.4. Formação da coisa julgada. Conclusão. Referências Bibliográficas.

\section{NOTAS INTRODUTÓRIAS}

A sociedade atual, enquanto resultado de avanços tecnológicos, da industrialização, da globalização e do crescimento exponencial das cidades, caracteriza-se pela massificação das relações sociais, culminando na formação de relações jurídicas homogêneas que, ao chegarem ao Judiciário, formam a denominada litigiosidade de massa. Aliado a este movimento, a constitucionalização de direitos e o desenvolvimento dos Direitos Humanos no pós-Segunda Guerra Mundial, foram fundamentais no aumento vertiginoso das demandas seriadas. $^{2}$

Lado outro, o processo civil clássico, cujas concepções e institutos essenciais foram concebidas no seio da Revolução Francesa, tem caráter eminentemente individualista, pautado na negação ao Regime Absolutista. Nesse ínterim, a tutela atomizada dos litígios foi insuficiente diante da nova realidade social, o que propiciou o desenvolvimento de

${ }^{2}$ DIDIER JR., Fredie. ZANETI JR., Hermes. Curso de Direito Processual Civil: Processo Coletivo. 9. ed. Salvador: JusPodivm, 2014. v. 4. p. 32. 
Revista Eletrônica de Direito Processual - REDP.

Rio de Janeiro. Ano 10. Volume 17. Número 2. Julho a Dezembro de 2016

Periódico Semestral da Pós-Graduação Stricto Sensu em Direito Processual da UERJ

Patrono: José Carlos Barbosa Moreira. ISSN 1982-7636. pp. 76-100

www.redp.uerj.br

tutelas coletivas de direitos, que no Brasil foram incorporadas por meio das ações coletivas para tutela de direitos difusos, coletivos stricto sensu e individuais homogêneos, estruturadas com base no modelo das class actions norte-americanas.

Nada obstante, as ações coletivas de tutela de direitos coletivos, por si só, não conseguem contingenciar de forma satisfatória a litigiosidade seriada. Dada insuficiência se justifica nas próprias características das ações coletivas no sistema brasileiro que optou por acolher as tutelas coletivas, sem que, todavia, houvesse interferências na tutela individual. Disso decorre, pois, a extensão secundum eventum litis de coisa julgada coletiva, bem como a possibilidade de ajuizamento simultâneo de demandas individuais. ${ }^{3}$ Somado a isso, a jurisprudência e a legislação caminharam no sentido de restringir a aplicabilidade das tutelas coletivas em diversas matérias, como em causas tributárias e previdenciárias. $^{4}$

Consequência disso, a tradicional tutela coletiva de direitos no sistema brasileiro mostrou-se inadequada para resolver o problema da litigiosidade repetitiva.

Nesse cenário, o Código de Processo Civil de 2015 (Lei n 13.105/15) consagra um novo instituto ao processo civil brasileiro que tem a função de solucionar os litígios repetitivos, a partir da racionalização das decisões judiciais, com uma resposta rápida à solução dos litígios de massa. ${ }^{5}$ Trata-se do Incidente de Resolução de Demandas Repetitivas (IRDR) que, ao lado dos Recursos Especiais e Extraordinários Repetitivos (REER) formam o modelo de julgamento de casos repetitivos consolidado pelo art. 928 do $\mathrm{CPC} / 15$.

O IRDR é implementado pelo legislador processual enquanto mecanismo de tutela de litígios repetitivos com vistas a remediar o problema de assoberbamento do Judiciário e imprevisibilidade da prestação jurisdicional, ainda no primeiro grau de jurisdição, através do julgamento por amostragem em hipóteses de efetiva repetição de litígios sobre a mesma questão de direito que crie um risco real de ofensa à isonomia e à segurança jurídica. ${ }^{6}$

\footnotetext{
${ }^{3}$ MENDES, Aluísio Gonçalves de Castro. TEMER, Sofia. O incidente de resolução de demandas repetitivas do novo Código de Processo Civil. Revista de Processo, São Paulo, v. 243, p. 283-331, maio 2015 (texto digital).

${ }^{4}$ Art. $1^{\text {a }}$, parágrafo único, da Lei n. 7.347/85.

${ }^{5}$ MARINONI, Luiz Guilherme. Comentários aos artigos 926 a 928 do CPC/15. In: DANTAS, Bruno; DIDIER JR., Fredie; WAMBIER, Teresa Arruda Alvim; TALAMINI, Eduardo (Coord.). Breves comentários ao Código de Processo Civil. São Paulo: RT, 2015. p. 2081.

6 "Sob um primeiro aspecto, as relações homogeneizadas ganharam terreno sobre os vínculos individualizados, sem, no entanto, extingui-los. Os dois passaram a coexistir, ocupando espaços que ora se
} 
Revista Eletrônica de Direito Processual - REDP.

Rio de Janeiro. Ano 10. Volume 17. Número 2. Julho a Dezembro de 2016

Periódico Semestral da Pós-Graduação Stricto Sensu em Direito Processual da UERJ

Patrono: José Carlos Barbosa Moreira. ISSN 1982-7636. pp. 76-100

wWW.redp.uerj.br

Tal fenômeno vem sendo identificado como o "microssistema dos casos

repetitivos"7, e nesse sentido se encontra a redação do enunciado n. 345 do Fórum

Permanente de Processualistas $\mathrm{Civil}^{8}$. Esse "microssistema" seria composto inclusive pela

Lei n. 13.015/14, que dispõe sobre os recursos de revista repetitivos, atinentes ao processo do trabalho.

Diante deste quadro, o presente artigo presta-se a perquirir acerca da tutela de casos repetitivos na solução de litígios repetitivos e sua relação com o direito coletivo. Para tanto, é necessário ter como ponto de partida o processo coletivo e seus conceitos necessários. Será realizada, em sequência, uma análise comparada dos casos repetitivos e das ações coletivas, acerca de seus elementos, garantias processuais e efeitos. Assim, ao final, o presente trabalho pretende desenvolver o processo coletivo brasileiro, até então essencialmente formado pelas ações coletivas para tutela dos direitos difusos, coletivos stricto sensu e individuais homogêneos, também como gênero da técnica dos casos repetitivos.

confundem, ora se distinguem. Indivíduo e massa passam a conviver simultaneamente, sem que um deva excluir o outro. Um dos desafios da sociedade passa a ser a manutenção do equilíbrio entre ambos. Não é possível pensar somente num modelo massificado, sob pena de acabar com a identidade e a significação do indivíduo e de sua diferença em relação ao outro. Mas também não é possível conceber um paradigma puramente individualista, dada a dinâmica da inserção social em grupos, classes ou categorias, com vantagens para todos os que os integram e problemas que afligem à coletividade. A obtenção destes proveitos e a solução destes problemas são inalcançáveis ou de dificílimo alcance para uma só pessoa. Daí a relevância do grupo". (BASTOS, Antonio Adonias Aguiar. Situações jurídicas homogêneas: um conceito necessário para o processamento das demandas de massa. Revista de Processo, São Paulo, v. 186, p. 87-107, ago. 2010 (texto digital)).

${ }^{7}$ Nada obstante a doutrina informe a formação de um "microssistema" dos casos repetitivos, necessária se faz uma avaliação crítica desta denominação, sob pena de vulgarizar dada terminologia. Vale ressaltar que a figura dos microssistemas surgiu na era da Descodificação e tem como característica marcante a existência de um complexo de leis extravagantes com premissas e diretrizes próprias, num movimento de retirada da função preponderante dos códigos. A outro giro, a positivação dos casos repetitivos no direito brasileiro se deu no bojo do Código de Processo Civil, diploma central em matéria processual, inexistindo, pois, um complexo normativo a reger questão específica - o que não impede o diálogo entre as fontes na interpretação dos institutos de IRDR, REER e recurso de revista repetitivos. Todavia, não se pode ignorar que o Código de Processo Civil de 2015 é fruto de um novo contexto jurídico, qual seja, a Era da Recodificação. Diante de tais considerações, reputamos válida uma investigação mais profunda sobre a real existência ou não de um "microssistema" de casos repetitivos - o que, num primeiro momento, julgamos que não é o que parece ser -, entretanto, tal pesquisa foge dos limites do presente artigo. Sem embargo, eventual menção a essa expressão refere-se ao conjunto normativo de tutela dos casos repetitivos no direito processual civil e no direito processual do trabalho.

${ }^{8}$ Enunciado n. 345 do Fórum Permanente de Processualistas Civis: "O incidente de resolução de demandas repetitivas e o julgamento dos recursos extraordinários e especiais repetitivos formam um microssistema de solução de casos repetitivos, cujas normas de regência se complementam reciprocamente e devem ser interpretadas conjuntamente". 
Revista Eletrônica de Direito Processual - REDP.

Rio de Janeiro. Ano 10. Volume 17. Número 2. Julho a Dezembro de 2016

Periódico Semestral da Pós-Graduação Stricto Sensu em Direito Processual da UERJ

Patrono: José Carlos Barbosa Moreira. ISSN 1982-7636. pp. 76-100

www.redp.uerj.br

\section{PROCESSO COLETIVO E SEUS DIFERENTES MODELOS: CONCEITUAÇÕES NECESSÁRIAS}

No estudo de qualquer ciência é imprescindível limitar o objeto em análise, conceituando-o e enquadrando-o no sistema que o circunda de maneira precisa e adequada. Nesse sentido, enquanto conceito primário do estudo sobre o tema, define-se processo coletivo como o gênero de processo jurisdicional no qual é deduzida uma relação jurídica litigiosa coletiva. ${ }^{9}$ Logo, o reconhecimento de um grupo é a essência para a identificação do processo coletivo, seja ele no polo ativo ou passivo da demanda. ${ }^{10}$ Nas palavras de Fredie Didier Jr. e Hermes Zaneti Jr. ${ }^{11}$ :

O processo coletivo pertence ao gênero processual jurisdicional: procedimento (ato complexo) destinado à produção de norma jurídica em razão do exercício da jurisdição. [...]

A especificidade do processo coletivo encontra-se no objeto litigioso.

O processo é coletivo se a relação jurídica litigiosa é coletiva. Uma relação jurídica é coletiva se em um de seus termos, como sujeito ativo ou passivo, encontra-se um grupo (comunidade, categoria, classe etc; designa-se qualquer um deles pelo gênero grupo).

Imersos na concepção de processo coletivo, em uma análise comparada, diferentes modelos de tutela jurisdicional de direitos coletivos se desenvolveram, sendo dois destes os

\footnotetext{
9 DIDIER JR., Fredie. ZANETI JR., Hermes. Conceito de processo jurisdicional coletivo. Revista de Processo, São Paulo, ano 39, v. 229, p. 273-280, mar. 2014. p. 274-275.

${ }^{10}$ Além disso, a classificação de um processo como coletivo passa pela identificação de uma situação jurídica coletiva, ou seja, nele se afirma um direito ou um dever coletivo. Nesse sentido, em edição recente de obra conjunta, Fredie Didier Jr. e Hermes Zaneti Jr. preceituam que: "O processo é coletivo se a relação jurídica litigiosa (a que é objeto do processo) é coletiva. Uma relação jurídica é coletiva se em um de seus termos, como sujeito ativo ou passivo, encontra-se um grupo (comunidade, categoria, classe etc.; designa-se qualquer um deles pelo gênero grupo) e, se no outro termo, a relação jurídica litigiosa envolver direito (situação jurídica ativa) ou dever ou estado de sujeição (situações jurídicas passivas) de um determinado grupo. Assim, presentes o grupo e a situação jurídica coletiva, está-se diante de um processo coletivo". (DIDIER JR., Fredie. ZANETI JR., Hermes. Curso de Direito Processual Civil: Processo Coletivo. 10. ed. Salvador: JusPodivm, 2016. v. 4. p. 168).

11 DIDIER JR., Fredie. ZANETI JR., Hermes. Conceito de processo jurisdicional coletivo. Revista de Processo, São Paulo, ano 39, v. 229, p. 273-280, mar. 2014. p. 274-275.
} 
Revista Eletrônica de Direito Processual - REDP.

Rio de Janeiro. Ano 10. Volume 17. Número 2. Julho a Dezembro de 2016

Periódico Semestral da Pós-Graduação Stricto Sensu em Direito Processual da UERJ

Patrono: José Carlos Barbosa Moreira. ISSN 1982-7636. pp. 76-100

www.redp.uerj.br

principais expoentes tradicionalmente citados pelos juristas: o modelo das Class Actions norte-americanas e o modelo da Verbandsklage alemã. ${ }^{12}$

As Class Actions norte-americanas têm origem na Federal Rules of Civil Procedure de 1938, com vistas a tutelar direitos coletivos lato sensu de forma ampla ${ }^{13}$, no qual há a substituição do grupo de indivíduos com interesse comum, vítimas de uma lesão de massa, por um representante adequado, que pode ser uma ou mais pessoas. ${ }^{14}$

Tal modelo de tutela jurisdicional de direitos coletivos tem como principais características, além da legitimidade de um ou alguns indivíduos exercerem a adequada representação do grupo, a formação de coisa julgada pro et contra para toda a classe representada. Assim sendo, a demanda coletiva, independentemente de seu resultado, vinculará todos os membros do grupo. Em contraponto a isso, conforme leciona Michele Taruffo $^{15}$, o mecanismo do opting out permite ao titular do direito individual colocar-se a salvo dos efeitos da sentença coletiva, caso considere mais vantajoso fazer valer seu direito por meio de uma ação individual. Por esse motivo, a existência de uma class action deve ser amplamente divulgada, garantindo aos membros do grupo a adequada notificação e, assim lhes possibilitando o exercício do right to opt out.

Já o modelo da Verbandsklage, bastante difundido na Europa-Continental, tutela direitos de grupos de forma mais restrita do que as class actions norte-americanas e as ações coletivas brasileiras, estando preeminentemente voltado a tutela de obrigações de

12 ZANETI JR., Hermes. Três Modelos de Processo Coletivo no Direito Comparado: Class Actions, Ações Associativas/Litígios Agregados e o "Processo Coletivo: Modelo Brasileiro". Revista Eletrônica de Processos Coletivos, Porto Alegre, v. 5, n. 3, jul./set. 2014. Disponível em: <.http://www.processoscoletivos.net/revista-eletronica/63-volume-4-numero-3-trimestre-01-07-2014-a-3009-2014/1460-tres-modelos-de-processo-coletivo-no-direito-comparado-class-actions-acoooes-associativaslitigios-agregados-e-o-processo-coletivo-modelo-brasileiro>. Acesso em: 24 abr. 2016.

$13 \mathrm{O}$ modelo de class actions tem como escopo garantir a economia processual, ante a possibilidade de milhares de ações individuais serem substituídas por uma única ação coletiva, bem como o acesso à Justiça, por se tratar de um instrumento prático de efetivação de direitos, especialmente diante de hipóteses em que o prejuízo individual é ínfimo e, portanto, desproporcional se comparado com os desgastes de uma ação judicial (small claim class actions). Somado a isso, as class actions objetivam garantir a efetivação do direito material, sendo um instrumento de realização de políticas públicas, visto que têm como efeito o estímulo ao cumprimento voluntário do direito, estimulando resultados deterrentes. Outra característica marcante desse modelo de tutela jurisdicional de direitos coletivos é a atribuição de amplos poderes ao juiz na condução do processo, podendo, por exemplo, reunir ações propostas separadamente, se assim convir ou suspender o processo, caso considere que insuficiente a defesa técnica. (GIDI, Antonio. A class action como instrumento de tutela coletiva dos direitos: as ações coletivas em uma perspectiva comparada. São Paulo: RT, 2007. p 2539).

14 BUENO. Cassio Scarpinella. As class actions norte-americanas e as ações coletivas brasileiras: pontos para uma reflexão conjunta. Revista de Processo, São Paulo, v. 82, p. 92-151, 1996 (texto digital).

${ }_{15}$ TARUFFO, Michele. Modelo de tutela jurisdicional de los interesses colectivos. Tradução de Juan Carlos Guayacán Ortiz. Bogotá: Revista de Derecho Privado, 2005. p. 30. 
Revista Eletrônica de Direito Processual - REDP.

Rio de Janeiro. Ano 10. Volume 17. Número 2. Julho a Dezembro de 2016

Periódico Semestral da Pós-Graduação Stricto Sensu em Direito Processual da UERJ

Patrono: José Carlos Barbosa Moreira. ISSN 1982-7636. pp. 76-100

www.redp.uerj.br

fazer e não-fazer ${ }^{16}$. Após algumas alterações, porém, passou-se a admitir de maneira

temperada ações condenatórias de caráter opt in, e por isso, a doutrina classifica tais procedimentos como "litígios agregados". ${ }^{17}$

O modelo de class actions não é muito bem aceito no direito europeu, tendo em vista o grande impacto econômico que condenações coletivas podem causar, bem como em razão de questões dogmáticas segundo as quais a tutela de direitos deve ser mantida na esfera individual. ${ }^{18}$ Com efeito, as ações associativas (Verbandsklage) não reforçam a eficácia deterrente de prevenção geral dos ilícitos com a mesma intensidade que os modelos de class actions.

As Verbandsklage têm como características centrais a especial legitimação ativa das associações, pela qual se escolhe um sujeito para tutelar em nome próprio direito que passa a ser considerado próprio, o distanciamento extremo da tutela de direitos individuais, bem como a excepcionalidade das hipóteses em que a associação defende de fato um interesse supraindividual, posto que na maior parte das situações, a associação somente poderá atuar mediante a autorização do titular da relação jurídica individual. ${ }^{19}$

Por sua vez, o processo coletivo pátrio foi largamente influenciado pelo modelo de class actions, que é notadamente o mais difundido dentre sistemas jurídicos que adotam o

\footnotetext{
16 ZANETI JR., Hermes. Três Modelos de Processo Coletivo no Direito Comparado: Class Actions, Ações Associativas/Litígios Agregados e o "Processo Coletivo: Modelo Brasileiro". Revista Eletrônica de Processos Coletivos, Porto Alegre, v. 5, n. 3, jul./set. 2014. Disponível em: <.http://www.processoscoletivos.net/revista-eletronica/63-volume-4-numero-3-trimestre-01-07-2014-a-3009-2014/1460-tres-modelos-de-processo-coletivo-no-direito-comparado-class-actions-acoooes-associativaslitigios-agregados-e-o-processo-coletivo-modelo-brasileiro>. Acesso em: 24 abr. 2016.

${ }^{17}$ Ibid.

18 "The reasons why many European and in particular German legal scholars are opposed to US class actions seem to be twofold. On the one hand, European legal scholars emphasize for dogmatic reasons that claims should be kept individual, and should be decided on a case by case basis. This coincides with a sceptical view on a Law\&Economics-perspective that is mainly interested in the incentive effects of litigation. On the other hand, it is argued that US class actions support frivolous claims, i.e. claims that have little chances of prevailing in the courtroom, but are mainly led to trigger settlements. However, it needs to be emphasized that incentives for frivolous claims are not necessarily associated with opt-out procedures, but rather follow from some specic features of the American law". (HALFMEIER, Axel; FEESS, Eberhard. The German Capital Markets Model Case Act (KapMuG) a European role model for increasing the efficiency of capital markets? Analysis and suggestions for reform. SSRN, jan. 2012. Disponível em: < http://papers.ssrn.com/sol3/papers.cfm?abstract_id=1684528 >. Acesso em: 30 abr. 2016).

19 ZANETI JR., Hermes. Três Modelos de Processo Coletivo no Direito Comparado: Class Actions, Ações Associativas/Litígios Agregados e o "Processo Coletivo: Modelo Brasileiro". Revista Eletrônica de Processos Coletivos, Porto Alegre, v. 5, n. 3, jul./set. 2014. Disponível em: <.http://www.processoscoletivos.net/revista-eletronica/63-volume-4-numero-3-trimestre-01-07-2014-a-3009-2014/1460-tres-modelos-de-processo-coletivo-no-direito-comparado-class-actions-acoooes-associativaslitigios-agregados-e-o-processo-coletivo-modelo-brasileiro>. Acesso em: 24 abr. 2016.
} 
Revista Eletrônica de Direito Processual - REDP.

Rio de Janeiro. Ano 10. Volume 17. Número 2. Julho a Dezembro de 2016

Periódico Semestral da Pós-Graduação Stricto Sensu em Direito Processual da UERJ

Patrono: José Carlos Barbosa Moreira. ISSN 1982-7636. pp. 76-100

www.redp.uerj.br

processo coletivo. ${ }^{20} \mathrm{O}$ modelo brasileiro de processo coletivo, porém, assumiu peculiaridades próprias que lhes garantiram autonomia em relação ao modelo norteamericano. ${ }^{21}$ Nesse limiar, Hermes Zaneti $\mathrm{Jr}^{22}$, complementando a concepção dúplice de modelos de tutela coletiva centrados nas Verbandsklage e nas class actions, defende o processo coletivo brasileiro enquanto um terceiro modelo de processo coletivo à luz do Direito Comparado.

As características centrais do modelo brasileiro de processo coletivo, conforme esse entendimento, são o interesse público primário, a não-taxatividade dos direitos e a atipicidade da ação, permitindo-se uma tutela ampla de direitos, por meio de todas as ações aptas para tal fim. ${ }^{23}$ Ademais, o modelo pátrio discorre de forma particular sobre a legitimação por substituição processual ativa e passiva, a extensão subjetiva da coisa julgada secundum eventum litis unicamente para beneficiar os titulares dos direitos individuais e o modo de produção secundum eventum probationis, hipótese em que por insuficiência de provas a sentença não fará coisa julgada.

Associado às técnicas representativas de tutela de direitos coletivos, tem ganhado destaque nos ordenamentos jurídicos estrangeiros mecanismos de julgamento por amostragem de casos repetitivos na forma de tutela de litígios agregados, no qual há a fixação de uma tese jurídica aplicável aos casos em curso que veiculem a mesma controvérsia. ${ }^{24}$ Nessas técnicas, o grupo em litígio é formado pelo somatório de ações individuais e somente aqueles que ajuizaram suas respectivas demandas ficarão vinculados pelo julgamento, sendo, pois, espécie de tutela opt in, tal qual as ações associativas.

Ainda que os casos repetitivos tenham em sua origem ações individuais, há a formação de um grupo litigante, elemento essencial no conceito de processo coletivo conforme demonstrado supra. Tal grupo, todavia, somente é ficticiamente formado a partir da admissão do incidente ou da seleção do recurso paradigma, assim, estar-se-á diante de um procedimento coletivo no momento em que for identificado em concreto uma situação

\footnotetext{
20 Ibid.

21 Ibid.

${ }^{22}$ Ibid.

${ }^{23}$ Ibid.

${ }^{24}$ Cita-se o inglês Group Litigation Order (GLO) e o alemão Kapitalanleger-Musterverfahren (KapMug) como as principais técnicas de julgamento de casos repetitivos no Direito Comparado.
} 
Revista Eletrônica de Direito Processual - REDP.

Rio de Janeiro. Ano 10. Volume 17. Número 2. Julho a Dezembro de 2016

Periódico Semestral da Pós-Graduação Stricto Sensu em Direito Processual da UERJ

Patrono: José Carlos Barbosa Moreira. ISSN 1982-7636. pp. 76-100

www.redp.uerj.br

jurídica homogênea deduzida em juízo por meio de sucessivos casos idênticos postulados individualmente. ${ }^{25}$

Desse modo, no processo coletivo dos casos repetitivos não há a formação $a$ priori do grupo tutelado, como ocorre nos modelos tradicionais de tutela coletiva ${ }^{26}$, mas verificase a aglutinação de ações individuais previamente propostas após a percepção de que estas veiculam a mesma tese jurídica, permitindo o julgamento conjunto, para fins de economia processual e harmonização do sistema. Essa formação diferida do grupo tutelado, porém, não tem condão de afastar os casos repetitivos do conceito de processo coletivo no direito brasileiro como tutela de grupo conforme acima elucidado. ${ }^{27}$

A tutela dos casos repetitivos se enquadra, nesse sentido, como mecanismo de processo coletivo, desenvolvido como técnica de solução de litígios repetitivos. Consiste em incidentes de julgamento de questões comuns pelos quais há a fixação de tese uma jurídica geral a partir dos casos representativos da controvérsia, aplicável aos demais casos idênticos em tramitação.

\section{AS DUAS TÉCNICAS DE PROCESSO COLETIVO: AS AÇÕES COLETIVAS E OS CASOS REPETITIVOS}

\footnotetext{
${ }^{25}$ Esclarece Hermes Zaneti Jr. acerca dos casos repetitivos que, "nesses casos, o grupo é identificado a partir das ações ajuizadas que veiculem a mesma tese jurídica, e essa tese jurídica irá constituir a situação jurídica coletiva deduzida em juízo". (ZANETI JR., Hermes. Notas sobre o processo coletivo e os casos repetitivos no sistema do novo CPC/2015: comentários ao art. 928. Revista Forense, Rio de Janeiro, ano 111, v. 421, p. 269-276, jan./jun. 2015. p. 271).

${ }^{26}$ No Brasil, conforme a classificação de direitos coletivos lato sensu adotada pelo CDC (art. 81, parágrafo único), os direitos difusos têm o grupo formado em decorrência da lesão, por pessoas ligadas por uma circunstância de fato. Nos direitos coletivos stricto sensu, o grupo é preexistente à lesão, formado por pessoas ligadas por uma relação jurídica base. Por fim, nos direitos individuais homogêneos, o grupo se reconhece pelos interesses em comum decorrentes da lesão. A outro giro, a formação do grupo na tutela dos casos repetitivos está umbilicalmente relacionada a judicialização do conflito.

${ }^{27}$ Ainda sob a égide da codificação processual civil de 1973, Fredie Didier Jr. e Hermes Zaneti Jr. já identificavam o mecanismo de julgamento agregado de recursos especiais e extraordinários que veiculavam a mesma tese jurídica como espécie de processo coletivo, de modo que, na ausência de normas, aplicava-se subsidiariamente o do microssistema do processo coletivo. Nesse sentido, aduziram: "O procedimento para a fixação da tese jurídica (arts. 543-B e 543-C do CPC), no julgamento dos recursos especiais e extraordinários repetitivos, possui como objeto litigioso uma situação jurídica coletiva (situações jurídicas individuais homogêneas). É, assim, espécie de processo coletivo. Por isso, a ele devem ser aplicadas, subsidiariamente, as regras do processo coletivo. Exatamente em razão disso, a desistência do recurso pelo recorrente somente pode ser eficaz em relação ao processo para o julgamento do objeto litigioso do seu recurso, que é individual; em relação ao processo para a fixação da tese, a desistência é inócua, exatamente como é inócua, de regra, no direito brasileiro, a desistência em processos coletivos (art. $9^{\circ}$ da Lei 4.717/1965; art. $5^{\circ}$, $\$ 3^{\circ}$, da Lei 7.347/1985; arts. $5^{\circ}$ e 16 da Lei 9.868/1999)". (DIDIER JR., Fredie. ZANETI JR., Hermes. Conceito de processo jurisdicional coletivo. Revista de Processo, São Paulo, ano 39, v. 229, p. 273-280, mar. 2014. p. 280).
} 
Revista Eletrônica de Direito Processual - REDP.

Rio de Janeiro. Ano 10. Volume 17. Número 2. Julho a Dezembro de 2016

Periódico Semestral da Pós-Graduação Stricto Sensu em Direito Processual da UERJ

Patrono: José Carlos Barbosa Moreira. ISSN 1982-7636. pp. 76-100

www.redp.uerj.br

A tendência de refrear a realidade da litigiosidade de massa reverberou no Código de Processo Civil de 2015, que ampliou os mecanismos de julgamento de casos repetitivos, implementando para primeiro grau de jurisdição o incidente de resolução de demandas repetitivas - considerada pelos juristas da comissão elaboradora do novo Código como sua maior inovação ${ }^{28}-\mathrm{e}$, aperfeiçoando no âmbito dos recursos repetitivos as técnicas já previstas para a solução de recursos especiais e extraordinários repetitivos (art. 543-B e art. 543-C do CPC de 1973).

Por seu turno, os casos repetitivos apresentam um perfil particular, não se identificando com as lides individuais, tampouco com as ações coletivas tradicionais no direito pátrio, sendo-lhe dado regime jurídico próprio. ${ }^{29}$

Desse modo, com a entrada em vigor do Código de Processo Civil de 2015, passaram a coexistir no processo coletivo brasileiro as ações coletivas para tutela dos direitos coletivos lato sensu e os casos repetitivos, previstos no bojo da nova codificação processual civil, para tutela das questões jurídicas comuns.

Nesse diapasão, com vistas ao uso adequado de cada um dos institutos, necessário se faz pontuar e sistematizar as principais distinções dessas duas espécies de processos coletivos, o que será feito a seguir.

\subsection{OBJETO}

Na dogmática do direito brasileiro, as ações coletivas instrumentalizam a tutela dos direitos difusos, enquanto aqueles titularizados por pessoas indeterminadas ligadas por uma circunstância de fato, dos direitos coletivos em sentido estrito, cuja titularidade pertence a grupo, categoria ou classe de pessoas ligadas entre si ou com a parte contrária por uma relação jurídica base, e dos direitos individuais homogêneos, entendidos como

\footnotetext{
${ }^{28}$ NUNES, Dierle. Processualismo constitucional e democrático e o dimensionamento de técnicas para a litigiosidade repetitiva: a litigância de interesse público e as tendências "não compreendidas" da padronização decisória. Revista de Processo, São Paulo, v. 199, p. 41-83, set. 2011 (texto digital).

29 CUNHA, Leonardo Carneiro da. O regime processual das causas repetitivas. Revista de Processo, São Paulo, ano 35, n. 179, p. 139-174, jan. 2010. p. 142-143. BASTOS, Antonio Adonias Aguiar. Situações jurídicas homogêneas: um conceito necessário para o processamento das demandas de massa. Revista de Processo, São Paulo, v. 186, p. 87-107, ago. 2010 (texto digital).
} 
Revista Eletrônica de Direito Processual - REDP.

Rio de Janeiro. Ano 10. Volume 17. Número 2. Julho a Dezembro de 2016

Periódico Semestral da Pós-Graduação Stricto Sensu em Direito Processual da UERJ

Patrono: José Carlos Barbosa Moreira. ISSN 1982-7636. pp. 76-100

www.redp.uerj.br

aqueles decorrentes de uma origem comum (art. 81, parágrafo único do Código de Defesa do Consumidor).

A tutela dos direitos coletivos lato sensu é a questão central das ações coletivas. Por uma opção política, o legislador restringiu o alcance de seu objeto ao vedar o uso de ação civil pública referente a matérias tributárias, previdenciárias ou relativas ao Fundo de Garantia por Tempo de Serviço (FGTS) e a outros fundos de natureza institucional. ${ }^{30}$

Do ponto de vista da litigiosidade seriada, parte da doutrina tem sustentado que o julgamento dos casos repetitivos seria instrumento de tutela apenas de direitos individuais homogêneos ${ }^{31}$, enquanto direitos cuja gênese se encontra em lesão de mesma procedência e, portanto, com caráter uniforme.

Em sentido oposto, porém, reconhece-se que o objeto dos casos repetitivos não se limita a apreciação de direitos individuais homogêneos, posto que as questões submetidas ao IRDR e aos recursos repetitivos podem se referir a direitos das mais variadas origens e tratar de relações jurídicas completamente diversas, conquanto que em meio a estes processos haja um ponto de discussão comum. ${ }^{32}$ A questão repetitiva ensejadora do incidente não necessariamente será a questão central dos processos afetados. Logo, é possível a suscitação do incidente de julgamento de causas repetitivas ainda que inexista identidade entre as causas de pedir e pedidos nas demandas que compõe o incidente. ${ }^{33}$ Ademais, o julgamento de casos repetitivos admite tanto questões de direito material quanto processual (art. 928, parágrafo único do CPC), embora limite-se a matéria unicamente de direito (art. 976, inciso I do CPC), uma vez que seu escopo é solucionar questão jurídica repetitiva, não comportando análise probatória.

Assim, não é requisito para a suscitação de um incidente de demandas ou recursos repetitivos que se alegue uma lesão de mesma origem, tal qual carece nos processos coletivos para defesa de direitos individuais homogêneos.

\footnotetext{
${ }^{30}$ Art. $1^{\circ}$, parágrafo único da Lei 7.347/85: "Não será cabível ação civil pública para veicular pretensões que envolvam tributos, contribuições previdenciárias, o Fundo de Garantia do Tempo de Serviço - FGTS ou outros fundos de natureza institucional cujos beneficiários podem ser individualmente determinados".

${ }^{31}$ DANTAS, Bruno. Comentários aos artigos 976 a 988 do CPC/15. In: DANTAS, Bruno; DIDIER JR., Fredie; WAMBIER, Teresa Arruda Alvim; TALAMINI, Eduardo (Coord.). Breves comentários ao Código de Processo Civil. São Paulo: RT, 2015, p. 2178.

${ }^{32}$ CABRAL, Antonio do Passo. Comentários aos artigos 976 a 988 do CPC/15. In: CABRAL, Antonio do Passo; CRAMER, Ronaldo. Comentários ao novo Código de Processo Civil. São Paulo: Forense, 2015, p. 1420.

${ }^{33}$ Ibid., p. 1420.
} 
Revista Eletrônica de Direito Processual - REDP.

Rio de Janeiro. Ano 10. Volume 17. Número 2. Julho a Dezembro de 2016

Periódico Semestral da Pós-Graduação Stricto Sensu em Direito Processual da UERJ

Patrono: José Carlos Barbosa Moreira. ISSN 1982-7636. pp. 76-100

www.redp.uerj.br

O que se exige dos casos repetitivos é que no bojo das múltiplas ações se discuta

uma questão comum acerca de direito material ou processual à qual deverá ser aplicada a mesma tese jurídica. Dessarte, a tutela dos casos repetitivos tem como objeto questões jurídicas repetitivas, de forma que os elementos objetivos das lides repetitivas se assemelham por debaterem a mesma questão de direito, mas não se confundem, uma vez que não estão vinculados no plano fático. ${ }^{34}$

Com base nessas premissas, Antonio Adonias Aguiar Bastos ${ }^{35}$ pondera que as lides repetitivas se identificam no plano abstrato e não no âmbito de cada situação concreta. Ou seja, diferentemente dos direitos individuais homogêneos cujo liame se encontra em uma situação concreta (lesão), as demandas seriadas se vinculam no plano das proposições.

Tal entendimento, contudo, não exclui os direitos individuais homogêneos do âmbito de apreciação das demandas repetitivas. A técnica de julgamento de litígios agregados não está restrita a interesses individuais, abrangendo igualmente as demandas coletivas, como prescreve os arts. 982 , I e $\S 3^{\circ}, 985, \mathrm{I}, 987, \S 2^{\circ}, 1.036, \S 1^{\circ}, 1.037$, II, do Código de Processo Civil de 2015.

É possível, pois, a conjugação do processamento dos casos repetitivos com as ações coletivas para a defesa de direitos coletivos lato sensu. Inclusive, defende-se que, havendo demandas coletivas que contemplem a questão jurídica repetitiva debatida, estas devem preferencialmente ser escolhidas como o caso-paradigma, pois a atuação dos legitimados extraordinários é conferida de maior legitimação política e social, além de, em tese, ter maior representatividade. ${ }^{36}$ Somado a isso, a escolha de uma ação coletiva como causapiloto tem o condão de emprestar à decisão dos casos repetitivos as amplas garantias do devido processo legal coletivo das ações coletivas. ${ }^{37}$

A preferência da ação coletiva face às ações individuais para a escolha do caso paradigma foi abordada pelo Fórum Permanente de Processualistas Civis com aprovação, nesse sentido, do enunciado n. 615:

\footnotetext{
34 BASTOS, Antonio Adonias Aguiar. Situações jurídicas homogêneas: um conceito necessário para o processamento das demandas de massa. Revista de Processo, São Paulo, v. 186, p. 87-107, ago. 2010 (texto digital).

${ }^{35}$ Ibid.

36 CABRAL, Antonio do Passo. A escolha da causa-piloto nos incidentes de resolução de processos repetitivos. Revista de Processo, São Paulo, ano 39, v. 231, p. 201-223, maio 2014. p. 219.

37 ZANETI JR., Hermes. Notas sobre o processo coletivo e os casos repetitivos no sistema do novo CPC/2015: comentários ao art. 928. Revista Forense, Rio de Janeiro, ano 111, v. 421, p. 269-276, jan./jun. 2015. p. 272.
} 
$\mathrm{Na}$ escolha dos casos paradigmas, devem ser preferidas, como representativas da controvérsia, demandas coletivas às individuais, observados os requisitos do art. 1.036, especialmente do respectivo $\S 6^{\circ}$. (Grupo: IRDR, Recursos Repetitivos e Assunção de competência).

A outro giro, frisa-se que nem sempre tal combinação será possível, de forma que a técnica da ação coletiva será inadequada para determinadas situações jurídicas, do mesmo modo que o julgamento de casos repetitivos será inaplicável em outras situações. ${ }^{38}$

A técnica da ação coletiva será o meio adequado de tutela quando o grupo for identificado em razão de um dano ou ameaça de dano, de natureza coletiva (direitos coletivos lato sensu), estando atrelado ao próprio direito material transindividual e indivisível. Em sentido diverso, a técnica de julgamento dos casos repetitivos será adequada quando o grupo se formalizar após as demandas serem levadas ao Judiciário e se constatar a efetiva repetição de processos sobre a mesma controvérsia unicamente de direito.

Assim, a discussão se, em tese, o convivente supérstite tem os mesmos direitos sucessórios que o cônjuge, é incabível por meio de uma ação coletiva, mas pode ser debatida por meio de um incidente de julgamento de casos repetitivos.

Já a responsabilidade de uma empresa mineradora por um acidente ambiental que causou prejuízo a uma comunidade não poderá ser objeto de discussão por meio de IRDR. Por outro lado, essa demanda poderá ser postulada através de uma ação coletiva.

Nesse sentido, o Tribunal de Justiça do Espírito Santo, em uma das primeiras decisões em sede de incidente de resolução de demandas repetitivas (IRDR $n^{\circ}$ 0009878-91.2016.8.08.0000) inadmitiu o pedido de instauração do incidente que pretendia discutir as centenas de ações de indenização ajuizadas em face da Samarco Mineração S/A no município de Colatina/ES em razão da ruptura de barragens na cidade de Mariana. Segundo a desembargadora-relatora, a matéria não envolve questão

${ }^{38}$ DIDIER JR., Fredie. ZANETI JR., Hermes. Ações coletivas e o incidente de julgamento de casos repetitivos - espécies de processo coletivo no direito brasileiro: aproximações e distinções. Revista de Processo, São Paulo, n. 256, p. 209-218, jun. 2016 (texto digital). 
Revista Eletrônica de Direito Processual - REDP.

Rio de Janeiro. Ano 10. Volume 17. Número 2. Julho a Dezembro de 2016

Periódico Semestral da Pós-Graduação Stricto Sensu em Direito Processual da UERJ

Patrono: José Carlos Barbosa Moreira. ISSN 1982-7636. pp. 76-100

www.redp.uerj.br

unicamente de direito, tampouco haveria, até aquele momento, divergência considerável nos pronunciamentos da primeira instância que justificasse o manejo do incidente.

\subsection{CARÁTER OPT IN OU OPT OUT}

Outra diferença central entre as técnicas das ações coletivas e do julgamento de casos repetitivos se traduz no sistema de vinculação opt in ou opt out dos indivíduos ao processo. $^{39}$

Assim, a tradicional tutela coletiva brasileira se dá por meio de procedimentos opt out. Por conseguinte, todos os membros do grupo serão atingidos pelos benefícios resultantes das ações coletivas, exceto se optarem por se colocarem a salvo do resultado do julgamento. ${ }^{40}$ Desse modo, do caráter opt out das ações coletivas decorre o fato de os titulares do direito serem abarcados pela sentença coletiva independentemente de qualquer tipo de manifestação de vontade prévia, bastando que legitimado extraordinário conduza o processo. O titular do direito individual poderá, ao final do processo, requerer o transporte in utilibus da sentença coletiva para a sua esfera individual de direitos.

Nas ações coletivas do modelo brasileiro, ressalta-se que o exercício do direito de auto-exclusão deve ser manifesto por meio da interposição de ação individual, com a devida ciência nos autos do processamento da ação coletiva, sem que a parte requeira a suspensão de sua lide individual (art. 104 do CDC). ${ }^{41}$

A outro giro, os casos repetitivos são espécies de tutela opt in, isto é, somente aqueles que ingressaram com demanda poderão ser beneficiados ou prejudicados com o resultado do julgamento. ${ }^{42}$ Outrossim, não é possível ao autor da demanda se auto excluir do grupo. Uma vez suscitado um incidente de julgamento de casos repetitivos, todas as ações em curso que veiculem a mesma tese jurídica serão automaticamente suspensas e,

\footnotetext{
39 Em sentido contrário, parte da doutrina vem entendendo que aos casos repetitivos não se aplicam os critérios de vinculação opt in e opt out. A saber, TEMER, Sofia. Incidente de Resolução de Demandas Repetitivas. Salvador: JusPodivm, 2016. p. 234.

40 ZANETI JR., Hermes. Notas sobre o processo coletivo e os casos repetitivos no sistema do novo CPC/2015: comentários ao art. 928. Revista Forense, Rio de Janeiro, ano 111, v. 421, p. 269-276, jan./jun. 2015. p. 271.

${ }^{41}$ DIDIER JR., Fredie. ZANETI JR., Hermes. Curso de Direito Processual Civil: Processo Coletivo. 10. ed. Salvador: JusPodivm, 2016. v. 4. p. 168.

${ }^{42}$ ZANETI JR., op. cit., p. 271, nota 39.
} 
Revista Eletrônica de Direito Processual - REDP.

Rio de Janeiro. Ano 10. Volume 17. Número 2. Julho a Dezembro de 2016

Periódico Semestral da Pós-Graduação Stricto Sensu em Direito Processual da UERJ

Patrono: José Carlos Barbosa Moreira. ISSN 1982-7636. pp. 76-100

www.redp.uerj.br

após o julgamento pelo Tribunal, a tese adotada no âmbito da questão comum será aplicada a todos os casos sobrestados.

Denota-se, portanto, que o caráter opt in dos casos repetitivos se limita a escolha de ingressar ou não com a ação, não sendo facultado à parte desvincular-se do grupo formado quando da suscitação de incidentes de julgamento repetitivo, ficando vinculado à tese firmada pelo Tribunal, posto que um dos objetivos do instituto é justamente homogeneizar as decisões em demandas idênticas.

A única maneira do titular da demanda em trâmite se excluir do grupo no julgamento de casos repetitivos sem ter que desistir da demanda é demonstrando de forma fundamentada que sua causa apresenta uma situação particular, distinta daquela em discussão no incidente, e que, portanto, exige solução jurídica diversa, à semelhança da figura do distinguishing para afastamento de precedente vinculante.

O mecanismo de distinguishing no âmbito de julgamento de casos repetitivos está regulamentado nos $\S 9^{\circ}$ a $13^{\circ}$ do art. 1.037 do CPC, que apesar de se referirem apenas aos recursos especiais e extraordinários repetitivos, se aplicam também ao processamento de casos repetitivos em primeiro grau. ${ }^{43}$ Desse modo, pinçado um processo, as partes serão intimadas da decisão de afetação, momento em que terão a faculdade de demonstrar, por meio de simples petição, a distinção entre a questão a ser decidida no processo e aquela a ser julgada no incidente. Esse é o teor do Enunciado n. 348 aprovado no Fórum Permanente de Processualistas Civis:

Os interessados serão intimados da suspensão de seus processos individuais, podendo requerer o prosseguimento ao juiz ou tribunal onde tramitarem, demonstrando a distinção entre a questão a ser decidida e aquela a ser julgada no incidente de resolução de demandas repetitivas, ou nos recursos repetitivos. (Grupo: Precedentes).

\subsection{LEGITIMIDADE}

\footnotetext{
${ }^{43}$ NUNES, Dierle. Comentários aos artigos 1036 a 1.041 do CPC/15. In: DANTAS, Bruno; DIDIER JR., Fredie; WAMBIER, Teresa Arruda Alvim; TALAMINI, Eduardo (Coord.). Breves comentários ao Código de Processo Civil. São Paulo: RT, 2015. p. 2320-2342. p. 2.331.
} 
Revista Eletrônica de Direito Processual - REDP.

Rio de Janeiro. Ano 10. Volume 17. Número 2. Julho a Dezembro de 2016

Periódico Semestral da Pós-Graduação Stricto Sensu em Direito Processual da UERJ

Patrono: José Carlos Barbosa Moreira. ISSN 1982-7636. pp. 76-100

www.redp.uerj.br

Conforme demonstrado em tópico anterior, a evolução das tutelas coletivas tradicionalmente se deu por meio de procedimentos representativos, tal como ocorre nos modelos de class actions, ações associativas e as ações coletivas no modelo brasileiro.

Essas ações representativas se assemelham por sujeitos determinados postularem direitos em nome da coletividade. No direito brasileiro, a regra da legitimação para as ações coletivas é a legitimação extraordinária, operada por meio da técnica da substituição processual, de modo que o sujeito substituído não é considerado parte no processo, que será conduzido exclusivamente pelo substituto, autorizado a tutelar direito alheio em nome próprio.

Embora esse método busque dar efetividade a valores de celeridade, eficiência e igualdade entre pequenos e grandes litigantes, há quem critique a técnica de legitimação extraordinária na tutela de direitos coletivos lato sensu, sub a alegação de ofensa ao acesso à Justiça dos titulares do direito individual. ${ }^{44}$ Para os defensores dessa tese, força-se um caráter homogêneo e massificado da coletividade representada que não seria satisfatoriamente contingenciada pelo legitimado extraordinário, visto tratar-se de terceiro estranho ao grupo lesionado, fato que poderia influenciar negativamente na qualidade da representação. ${ }^{45}$

Esses argumentos, no entanto, se esvaziam ao analisar a questão sob o ponto de vista da adequacy representation, posto que se torna inconcebível a figura do representante inadequado. Nesse sentido, tal qual o sistema norte-americano de class actions, o modelo brasileiro de ações coletivas perpassa pelo controle ope judice da representatividade adequada. Assim sendo, além da legitimidade conferida pelo legislador, o magistrado tem o dever de observar em concreto se o condutor do processo está agindo conforme os interesses dos membros do grupo. ${ }^{46}$

A representatividade adequada decorre da definição constitucional de devido processo legal e objetiva precipuamente garantir que o resultado da demanda coletiva seja

\footnotetext{
${ }^{44}$ DANTAS, Bruno. Jurisdição coletiva, ideologia coletivizante e direitos fundamentais. Revista de Processo, São Paulo, v. 251, p. 341-358, jan. 2016 (texto digital).

${ }^{45}$ CABRAL, Antonio do Passo. O novo procedimento-modelo (Musterverfahren) alemão: uma alternativa às ações coletivas. Revista de Processo, São Paulo, n. 147, p. 123-146, 2007. p. 124-125. DANTAS, Bruno. Jurisdição coletiva, ideologia coletivizante e direitos fundamentais. Revista de Processo, São Paulo, v. 251, p. 341-358, jan. 2016 (texto digital).

46 GIDI, Antonio. A representação adequada nas ações coletivas brasileiras: uma proposta. Revista de Processo, São Paulo, v. 108, p. 61-70, 2002. p. 68.
} 
Revista Eletrônica de Direito Processual - REDP.

Rio de Janeiro. Ano 10. Volume 17. Número 2. Julho a Dezembro de 2016

Periódico Semestral da Pós-Graduação Stricto Sensu em Direito Processual da UERJ

Patrono: José Carlos Barbosa Moreira. ISSN 1982-7636. pp. 76-100

www.redp.uerj.br

o mais próximo possível daquilo que os membros do grupo obteriam em eventuais ações individuais. ${ }^{47}$ Somado a isso, conforme mencionado anteriormente, o legislador processual instituiu a tutela coletiva de direitos sem sacrificar a possibilidade de tutela individual, de modo que a extensão da coisa julgada será secundum eventum litis, apenas para beneficiar os titulares do direito individual, bem como os membros do grupo são livres para propor ações individuais sem que isso induza em litispendência com a demanda coletiva (art. 104, CDC). Sob essa ótica, não se justifica a alegação de que a legitimidade extraordinária ofende em qualquer grau o acesso à Justiça.

Malgrado a discordância em relação às aludidas críticas ao sistema de legitimação extraordinária das ações coletivas, a doutrina que defende tal tese tem identificado nos incidentes coletivos dentro de processos individuais um abrandamento da substituição processual, tendo em vista que os membros do grupo tutelado são efetivamente partes nos processos de origem e conseguem manter, dentro de certos limites, suas individualidades na sua condução. ${ }^{48}$

Assim, enquanto a tutela de direitos coletivos lato sensu se dá por meio de procedimentos representativos operados através de mecanismos de legitimação extraordinária, os incidentes de julgamento de demandas repetitivas se concretizam por meio da legitimação ordinária em que os membros do grupo agem em nome próprio na defesa de direito próprio.

Contudo, ainda que não se aplique a sistemática de substituição processual no julgamento dos casos repetitivos, para que se efetivem os escopos de celeridade processual e uniformização das decisões faz-se necessário restringir parcialmente a participação direta dos litigantes na formação de convicção do órgão julgador no que tange a questão repetitiva. $^{49}$

Trata-se de um ponto sensível na doutrina, ante posicionamentos que defendem a inconstitucionalidade do incidente por ofensa ao contraditório em razão desta limitação ${ }^{50}$, o que, conduto, não se coaduna com o conceito contemporâneo de contraditório enquanto

\footnotetext{
${ }^{47}$ Ibid., p. 66-69.

${ }^{48}$ CABRAL. Antonio do Passo. O novo procedimento-modelo (Musterverfahren) alemão: uma alternativa às ações coletivas. Revista de Processo, São Paulo, n. 147, p. 123-146, 2007. p. 128.

49 TEMER, Sofia. Incidente de Resolução de Demandas Repetitivas. Salvador: JusPodivm, 2016. p. 136.

${ }^{50}$ ABBOUD, Georges. CAVALCANTI. Marcos de Araújo. Inconstitucionalidades do incidente de resolução de demandas repetitivas (IRDR) e os riscos ao sistema decisório. Revista de Processo, São Paulo, v. 240, p. 221-242, fev. 2015 (texto digital).
} 
Revista Eletrônica de Direito Processual - REDP.

Rio de Janeiro. Ano 10. Volume 17. Número 2. Julho a Dezembro de 2016

Periódico Semestral da Pós-Graduação Stricto Sensu em Direito Processual da UERJ

Patrono: José Carlos Barbosa Moreira. ISSN 1982-7636. pp. 76-100

www.redp.uerj.br

possibilidade de influenciar na decisão judicial, ainda que indiretamente. Além disso, o julgamento do incidente permitirá a participação da sociedade civil através de audiências públicas, bem como de órgãos e instituições que possam contribuir na formação da decisão (art. $927, \S 2^{\circ}$ e art. $138, \S 3^{\circ}$ ).

Desse modo, a limitação na participação direta dos litigantes ocorrerá por meio da seleção de apenas alguns casos representativos da controvérsia para apreciação do Tribunal. Desse modo, as partes dos processos afetados serão os porta-vozes das teses defendidas perante o órgão julgador. ${ }^{51}$ Nisso está a relevância da escolha das causas representativas da controvérsia, pois a efetividade do julgamento dependerá de defesa satisfatória das teses antagônicas alegadas pelos autores e réus das causas-paradigma. ${ }^{52}$

Em razão disso, a escolha das causas representativas deverá ser feita de maneira criteriosa e fundamentada. A recente legislação processual cria um direcionamento nesse sentido ao versar no art. 1.036, $\S 6^{\circ}$ do CPC que somente poderão ser selecionados como recursos representativos da controvérsia aqueles que contenham abrangente argumentação e discussão a respeito da questão a ser decidida. Todavia, somente tal previsão é insuficiente na definição dos critérios de escolha adequada da causa-piloto. O julgador deverá levar em consideração, além da qualidade e amplitude da argumentação, aspectos como a capacitação e a experiência das partes e de seus advogados na exposição dos argumentos, a pluralidade e representatividade dos sujeitos do processo de origem. ${ }^{53}$

Disso depreende-se que o magistrado, no âmbito da escolha das causas-paradigma no julgamento dos casos repetitivos, dentre outros critérios de seleção, deverá empreender o controle judicial da adequada representação ${ }^{54}$, de modo a aferir em concreto a

\footnotetext{
${ }^{51}$ CABRAL, op. cit., p. 135 , nota 47.

${ }^{52}$ TEMER, Sofia. Incidente de Resolução de Demandas Repetitivas. Salvador: JusPodivm, 2016. p. 138.

${ }^{53}$ Estes são alguns dos critérios minunciosamente abordados por Antonio do Passo Cabral em suas obras. CABRAL, Antonio do Passo. A escolha da causa-piloto nos incidentes de resolução de processos repetitivos. Revista de Processo, São Paulo, ano 39, v. 231, p. 201-223, maio 2014. p. 210-220.

${ }^{54}$ A mesma solução é apontada por Georges Abboud e Marcos de Araújo Cavalcanti, que concluíram, com base nos ensinamentos de Antonio Gidi para as ações coletivas que "o magistrado brasileiro, de lege lata, tem o dever de realizar o controle judicial da representação adequada no âmbito do IRDR, em observância à cláusula do devido processo legal. Cabe a ele verificar se os advogados e as partes representativas têm condições técnicas, morais, financeiras etc. de agir em juízo na defesa das posições jurídicas relacionadas às questões jurídicas discutidas nas demandas repetitivas. Deve verificar, também, se a causa pendente no tribunal abrange adequadamente a controvérsia repetitiva". (ABBOUD, Georges. CAVALCANTI. Marcos de Araújo. Inconstitucionalidades do incidente de resolução de demandas repetitivas (IRDR) e os riscos ao sistema decisório. Revista de Processo, São Paulo, v. 240, p. 221-242, fev. 2015 (texto digital)).
} 
Revista Eletrônica de Direito Processual - REDP.

Rio de Janeiro. Ano 10. Volume 17. Número 2. Julho a Dezembro de 2016

Periódico Semestral da Pós-Graduação Stricto Sensu em Direito Processual da UERJ

Patrono: José Carlos Barbosa Moreira. ISSN 1982-7636. pp. 76-100

www.redp.uerj.br

legitimação daqueles que irão intermediar os interesses do grupo perante o Judiciário, enquanto decorrência do princípio do devido processo legal coletivo.

Nesse ponto, os litígios agregados se aproximam das ações coletivas pautadas no modelo de class actions, uma vez que também dependem de um sistema ope judice de controle dos representantes do grupo. Há de se ressaltar, porém, que o controle da adequacy representation nas ações coletivas recai sobre o substituto processual, diferentemente dos casos repetitivos, em que o controle judicial recairá sobre as partes das causas afetadas.

Por fim, vale ressaltar que o controle da representação adequada para o IRDR e para os recursos repetitivos está relacionado aos sujeitos dos processos representativos da controvérsia que irão ter papel central na defesa das teses contrapostas durante o julgamento perante o Tribunal e em nada tem a ver com os legitimados para suscitar o incidente, elencados nos incisos do art. 977 do CPC.

\subsection{FORMAÇÃO DA COISA JULGADA}

Além das diferenças por ora apontadas, as ações coletivas e os casos repetitivos distanciam-se no que tange a estabilidade da decisão.

Nos procedimentos de tutela de direitos coletivos lato sensu há efetiva formação da res iudicata, porém com variações nos limites subjetivos e no modo de produção a depender da espécie de direitos coletivo tutelado: direito difuso, coletivo stricto sensu ou individual homogêneo. Assim, a coisa julgada coletiva abrangerá (limites subjetivos) de forma inter partes entre autor e réu em quaisquer espécies de direito coletivos lato sensu, além de ultra partes no caso de direitos coletivos stricto sensu (art. 103, II, CDC) e erga omnes quanto aos direitos difusos e individuais homogêneos (art. 103, I e III, CDC). ${ }^{55}$ No modo de produção, a coisa julgada coletiva se formará (limites objetivos) pro et contra, isto é, independente do resultado do processo, entre autor e réu da demanda coletiva, ressalvada a insuficiência de provas (secundum eventum probationis), e os efeitos da coisa julgada coletiva, erga omnes ou ultra partes, somente se estendem à esfera individual dos

55 DIDIER JR., Fredie. ZANETI JR., Hermes. Curso de Direito Processual Civil: Processo Coletivo. 10. ed. Salvador: JusPodivm, 2016. v. 4. p. 394. 
Revista Eletrônica de Direito Processual - REDP.

Rio de Janeiro. Ano 10. Volume 17. Número 2. Julho a Dezembro de 2016

Periódico Semestral da Pós-Graduação Stricto Sensu em Direito Processual da UERJ

Patrono: José Carlos Barbosa Moreira. ISSN 1982-7636. pp. 76-100

www.redp.uerj.br

titulares de direitos individuais que não houverem participado do processo no caso de procedência da ação coletiva em favor do grupo (secundum eventum litis $\left.{ }^{56}\right) .{ }^{57}$

A estabilidade processual das decisões proferidas em sede de IRDR e REER, por sua vez, merece ser analisada sob um viés dúplice. Isso porque o julgamento de casos repetitivos pode implicar em dupla vinculação ${ }^{58}$, pois ao mesmo tempo que se aplica aos casos em tramitação à época da propositura do incidente, a decisão em casos repetitivos potencialmente poderá formar precedente em relação a tese jurídica sopesada, hipótese que deverá ser feita interpretação operativa do case, vinculando os julgadores em demandas futuras $^{59}$ (art. 985, I e II, CPC/15). Nesse ponto, destaca-se a preocupação do legislador em garantir maior estabilidade e segurança jurídica ao sistema por meio da nova legislação processual, impondo aos Tribunais o dever de manter sua jurisprudência estável, integra e coerente. $^{60}$

Sob esta perspectiva, a estabilidade da decisão em casos repetitivos pode ser examinada tanto sob a ótica dos litígios agregados que o incidente se presta a solucionar, quanto do ponto de vista da tese jurídica a ser fixada, cujos efeitos poderão ser prospectivos.

Assim, a eficácia da decisão para os casos atuais induzirá na efetiva formação da coisa julgada, apenas podendo ser desfeita mediante os mecanismos próprios para esse fim (ação rescisória). Eventual superação do precedente fixado não possibilita a reapreciação das demandas apreciadas. Essa conclusão não poderia ser outra diante de um sistema jurídico norteado pelo valor de segurança jurídica.

\footnotetext{
56 Antonio Gidi assim esclarece sobre o modo de produção secundum eventum litis: "Enfim, o que é secundum eventum litis não é a formação da coisa julgada, mas a sua extensão 'erga omnes' ou 'ultra partes' à esfera jurídica individual de terceiros prejudicados pela conduta considerada ilícita na ação coletiva". (GIDI, Antonio. Coisa julgada e litispendência em ações coletivas. São Paulo: Saraiva, 1995. p. 73).

${ }^{57}$ DIDIER JR., ZANETI JR., op. cit., p. 399, nota 54.

${ }^{58}$ Em atenção a essa dupla vinculação dos precedentes, destaca-se que a aplicação da decisão em casos repetitivos às demandas atuais não prescinde da fundamentação analítica expressa no $\S 1^{\circ}$ do art. 489 do novo Código, posto que esta já terá sido suprida por força do julgamento do caso paradigma. Por outro lado, a aplicação da tese firmada no julgamento de casos repetitivos em casos futuros impõe o dever de fundamentação adequada e vedação da decisão-surpresa. (ZANETI JR., Hermes. Notas sobre o processo coletivo e os casos repetitivos no sistema do novo CPC/2015: comentários ao art. 928. Revista Forense, Rio de Janeiro, ano 111, v. 421, p. 269-276, jan./jun. 2015. p. 273).

${ }^{59}$ ZANETI JR., Hermes. Comentários aos artigos 926 a 928 do CPC/15. In: CABRAL, Antonio do Passo; CRAMER, Ronaldo. Comentários ao novo Código de Processo Civil. São Paulo: Forense, 2015. p. 1322.

${ }^{60}$ Art. 926, CPC/15: “Os tribunais devem uniformizar sua jurisprudência e mantê-la estável, íntegra e coerente".
} 
Revista Eletrônica de Direito Processual - REDP.

Rio de Janeiro. Ano 10. Volume 17. Número 2. Julho a Dezembro de 2016

Periódico Semestral da Pós-Graduação Stricto Sensu em Direito Processual da UERJ

Patrono: José Carlos Barbosa Moreira. ISSN 1982-7636. pp. 76-100

www.redp.uerj.br

Já a eficácia futura das decisões relativas aos casos repetitivos, embora possuam

estabilidade processual, esta não se dá na forma de coisa julgada. Tanto a decisão de inadmissibilidade do incidente quanto a decisão de mérito não podem ser renovadas livremente caso as circunstâncias fático-jurídicas permanecerem as mesmas. Isso posto, Antonio do Passo $\mathrm{Cabral}^{61}$ propõe que tal estabilidade teria natureza de "preclusão extraprocessual ceteris paribus", ou seja, mantido o status quo, o resultado alcançado deve permanecer estável.

A renovação do incidente para a reapreciação de sua admissibilidade ou de seu mérito depende da demonstração de mudanças fáticas ou jurídicas suficientes para alterar a decisão anterior. ${ }^{62}$ Outrossim, à revisão da tese fixada em julgamento de IRDR e REER aplicam-se as regras de transição que os Tribunais editam quando da superação de um entendimento pacífico, evitando rupturas abruptas. Desse modo, havendo modificação de precedente firmado em julgamento de casos repetitivos, incidem as disposições dos $\S \S 2^{\circ}$ a $4^{\circ}$ do art. 927, que prescrevem o amplo debate acerca da alteração, a possibilidade de modulação temporal dos efeitos da decisão e a obrigatoriedade de fundamentação adequada e específica.

\section{CONCLUSÃO}

Nosso objetivo neste trabalho foi abordar o modelo de julgamento de casos repetitivos positivado pelo CPC/15 no contexto maior ao qual está inserido, contrapondo-o às ações coletivas para a tutela de direitos coletivos lato sensu nos que tange a aspectos de conteúdo dos processos, vinculação dos sujeitos, legitimidade e estabilidade da decisão.

Diante do exposto, reconhecemos que, embora as ações coletivas e os casos repetitivos possuam características próprias e se desempenhem cada um ao seu modo, ambos são espécies do gênero processo coletivo.

O Código de Processo Civil de 2015, portanto, ampliou e aprimorou a tutela coletiva de direitos, tradicionalmente regulamentada por meio de legislação extravagante

\footnotetext{
${ }^{61}$ CABRAL, Antonio do Passo. Comentários aos artigos 976 a 988 do CPC/15. In: CABRAL, Antonio do Passo; CRAMER, Ronaldo. Comentários ao novo Código de Processo Civil. São Paulo: Forense, 2015, p. 1449.

${ }^{62}$ Ibid., p. 1450.
} 
Revista Eletrônica de Direito Processual - REDP.

Rio de Janeiro. Ano 10. Volume 17. Número 2. Julho a Dezembro de 2016

Periódico Semestral da Pós-Graduação Stricto Sensu em Direito Processual da UERJ

Patrono: José Carlos Barbosa Moreira. ISSN 1982-7636. pp. 76-100 www.redp.uerj.br

denominada microssistema do processo coletivo, através da sistematização da técnica de julgamento por amostragem centrada no art. 928 da codificação processual vigente.

Desse modo, as duas técnicas de processo coletivo se harmonizam no atual ordenamento jurídico processual com vistas e dirimir os entraves causados pela massificação de demandas. Busca-se, assim, conferir maior racionalidade e previsibilidade às decisões judiciais, bem como outorgar maior agilidade aos julgamentos de demandas seriadas que atualmente assoberbam o Poder Judiciário.

O bom manejo das duas técnicas, isolada ou conjuntamente, tem potencial para efetivar a adequada tutela de direitos pretendida pela ciência processual, conferindo avanços na concretização dos preceitos de isonomia, celeridade e segurança jurídica, desde que, obviamente, respeitadas as garantias do devido processo legal coletivo.

\section{REFERÊNCIAS BIBLIOGRÁFICAS}

ABBOUD, Georges. CAVALCANTI. Marcos de Araújo. Inconstitucionalidades do incidente de resolução de demandas repetitivas (IRDR) e os riscos ao sistema decisório. Revista de Processo, São Paulo, v. 240, p. 221-242, fev. 2015.

BASTOS, Antonio Adonias Aguiar. Situações jurídicas homogêneas: um conceito necessário para o processamento das demandas de massa. Revista de Processo, São Paulo, v. 186, p. 87-107, ago. 2010.

BUENO. Cassio Scarpinella. As class actions norte-americanas e as ações coletivas brasileiras: pontos para uma reflexão conjunta. Revista de Processo, São Paulo, v. 82, p. 92-151, 1996.

CABRAL, Antonio do Passo. A escolha da causa-piloto nos incidentes de resolução de processos repetitivos. Revista de Processo, São Paulo, ano 39, v. 231, p. 201-223, maio 2014. 
Revista Eletrônica de Direito Processual - REDP.

Rio de Janeiro. Ano 10. Volume 17. Número 2. Julho a Dezembro de 2016

Periódico Semestral da Pós-Graduação Stricto Sensu em Direito Processual da UERJ

Patrono: José Carlos Barbosa Moreira. ISSN 1982-7636. pp. 76-100 www.redp.uerj.br

. Comentários aos artigos 976 a 988 do CPC/15. In: ; CRAMER,

Ronaldo. Comentários ao Novo Código de Processo Civil. São Paulo: Forense, 2015, p. 1415- 1454.

O novo procedimento-modelo (Musterverfahren) alemão: uma alternativa às ações coletivas. Revista de Processo, São Paulo, n. 147, p. 123-146, 2007.

CUNHA, Leonardo Carneiro da. O regime processual das causas repetitivas. Revista de Processo, São Paulo, ano 35, n. 179, p. 139-174, jan. 2010.

DANTAS, Bruno. Comentários aos artigos 976 a 988 do CPC/15. In:

DIDIER JR., Fredie; WAMBIER, Teresa Arruda Alvim; TALAMINI, Eduardo (Coord.). Breves Comentários ao Código de Processo Civil. São Paulo: RT, 2015, p. 2.178-2198. Jurisdição coletiva, ideologia coletivizante e direitos fundamentais. Revista de Processo, São Paulo, v. 251, p. 341-358, jan. 2016.

DIDIER JR., Fredie. ZANETI JR., Hermes. Ações coletivas e o incidente de julgamento de casos repetitivos - espécies de processo coletivo no direito brasileiro: aproximações e distinções. Revista de Processo, São Paulo, v. 256, p. 209-218, jun. 2016.

. Conceito de processo jurisdicional coletivo. Revista de Processo, São Paulo, ano 39, v. 229, p. 273-280, mar. 2014.

. Curso de Direito Processual Civil: Processo Coletivo. 9. ed. Salvador: JusPodivm, 2014. v. 4.

Curso de Direito Processual Civil: Processo Coletivo. 10. ed. Salvador: JusPodivm, 2016. v. 4.

GIDI, Antonio. A class action como instrumento de tutela coletiva dos direitos: as ações coletivas em uma perspectiva comparada. São Paulo: RT, 2007. 
Rio de Janeiro. Ano 10. Volume 17. Número 2. Julho a Dezembro de 2016

Periódico Semestral da Pós-Graduação Stricto Sensu em Direito Processual da UERJ

Patrono: José Carlos Barbosa Moreira. ISSN 1982-7636. pp. 76-100 www.redp.uerj.br

A representação adequada nas ações coletivas brasileiras: uma proposta.

Revista de Processo, São Paulo, v. 108, p. 61-70, 2002.

Coisa julgada e litispendência em ações coletivas. São Paulo: Saraiva, 1995.

HALFMEIER, Axel; FEESS, Eberhard. The German Capital Markets Model Case Act (KapMuG) a European role model for increasing the ec ciency of capital markets? Analysis and suggestions for reform. SSRN, jan. 2012. Disponível em: <http://papers.ssrn.com/sol3/papers.cfm?abstract_id=1684528 >. Acesso em: 30 abr. 2016.

MARINONI, Luiz Guilherme. Comentários aos artigos 926 a 928 do CPC/15. In: DANTAS, Bruno; DIDIER JR., Fredie; WAMBIER, Teresa Arruda Alvim; TALAMINI, Eduardo (Coord.). Breves comentários ao Código de Processo Civil. São Paulo: RT, 2015. p. 2072-2083.

MENDES, Aluísio Gonçalves de Castro. TEMER, Sofia. O incidente de resolução de demandas repetitivas do novo Código de Processo Civil. Revista de Processo, São Paulo, v. 243, p. 283-331, maio 2015.

NUNES, Dierle. Comentários aos artigos 1036 a 1.041 do CPC/15. In: DANTAS, Bruno; DIDIER JR., Fredie; WAMBIER, Teresa Arruda Alvim; TALAMINI, Eduardo (Coord.). Breves comentários ao Código de Processo Civil. São Paulo: RT, 2015. p. 2320-2342.

Processualismo constitucional e democrático e o dimensionamento de técnicas para a litigiosidade repetitiva: a litigância de interesse público e as tendências “não compreendidas” da padronização decisória. Revista de Processo, São Paulo, v. 199, p. 41-83, set. 2011. 
Revista Eletrônica de Direito Processual - REDP.

Rio de Janeiro. Ano 10. Volume 17. Número 2. Julho a Dezembro de 2016

Periódico Semestral da Pós-Graduação Stricto Sensu em Direito Processual da UERJ

Patrono: José Carlos Barbosa Moreira. ISSN 1982-7636. pp. 76-100

www.redp.uerj.br

TARUFFO, Michele. Modelo de tutela jurisdicional de los interesses colectivos. Tradução

de Juan Carlos Guayacán Ortiz: Revista de Derecho Privado, Bogotá, n. 9, p. 23-33, 2005 .

TEMER, Sofia. Incidente de Resolução de Demandas Repetitivas. Salvador: JusPodivm, 2016 .

ZANETI JR., Hermes. Comentários aos artigos 926 a 928 do CPC/15. In: CABRAL, Antonio do Passo; CRAMER, Ronaldo. Comentários ao novo Código de Processo Civil. São Paulo: Forense, 2015. p. 1302-1332.

. Notas sobre o processo coletivo e os casos repetitivos no sistema do novo CPC/2015: comentários ao art. 928. Revista Forense, Rio de Janeiro, v. 421, p. 269-276, jan./jun. 2015.

Três Modelos de Processo Coletivo no Direito Comparado: Class Actions, Ações Associativas/Litígios Agregados e o "Processo Coletivo: Modelo Brasileiro". Revista Eletrônica de Processos Coletivos, Porto Alegre, v. 5, n. 3, jul./set. 2014.

Disponível em: <.http://www.processoscoletivos.net/revista-eletronica/63-volume-4numero-3-trimestre-01-07-2014-a-30-09-2014/1460-tres-modelos-de-processo-coletivono-direito-comparado-class-actions-acoooes-associativas-litigios-agregados-e-o-processocoletivo-modelo-brasileiro>. Acesso em: 24 abr. 2016. 